\title{
Modelling Professional Performance of Teachers' Scales in Libyan Schools
}

\author{
Khairi Saleh Shakuna, Norhisham Mohamad, Asbi B Ali \\ Management and Science University, Malaysia
}

\begin{abstract}
:
The aim of the current study was to develop a conceptual framework on Libyan teachers' professional performance. The study was carried among Libyan primary and secondary school teachers of English in Zawiya, in the west Region of Libya. The study adopted a survey that measured teachers' teaching skills, management skills, discipline and regularity, interpersonal, and professional development. A confirmatory factor analysis (CFA) was used for analysing the data through AMOS software. The results of the study showed that the proposed model is feasible and statistically valid in measuring teachers' professional performance. The findings of this study not only shed some light in the Libyan teachers' performance but it also can be used as an evaluation instrument by the school administrators in identifying and improving developmental needs.
\end{abstract}

Paper type: Research paper

Keywords: Teaching Skills, Management Skills, Discipline and Regularity, Interpersonal Skills, Professional Development, Teacher Professionalism, Professional Performance 


\section{Introduction}

Many teachers across the globe have been experiencing similar government interventions in remoulding teacher professionalism (Attinello et al., 2006; Day, 2002; Evans, 2011; Louden, 2000). To a great extent, the teaching profession is governed by the professional standard for teaching. As Louden (2000: 120) stated, professional standard for teaching refers to the standard what teachers need to comprehend and be able to perform. The standard also represents a performance yardstick for administrators or HR professionals to measure performance as well as identify and improve poor performer (Evans, 2011: 853). To a great extent, professional standard consists of a set of behavioural code of an occupational group (Evans, 2011; Louden 2000). In relation to that, professional performance of teachers' scale reflects the enacted version of teacher standard (Evans, 2011).

This study aims to test the validity of the professional performance of teachers' scales as a latent factor by testing the convergent validity known as the average variance extracted (AVE) for each dimension of the main scale, which are: teaching Skills, management skills, discipline and regularity, interpersonal and professional development as well as the items representing them (see Appendix). It also aimed to test the divergent validity known as shared variance (SV) among the investigated dimensions in order to be relying upon them in carrying out tests of correlations and effects or impact with other underlying factors.

\section{Literature Review}

\subsection{Education in Libya}

Ranked by WEF, Libya is $142^{\text {nd }}$ in the world (out of 144) for general quality of its education system (Rose, 2015). Since 2011, the civil war in Libya has caused a lot of damages to the country (ICEF Monitor, 2014). In 2014, the campus of the University of Benghazi was destroyed during the conflict (BTI, 2016). Due to the political unrest, the educational system in Libya suffers from the following issues: weak school administrations, poor teacher training, slow progress in revising and developing the curricula as well as inadequate teaching facilities (BTI, 2016; ICEF Monitor, 2014; Rose, 2015).

The Libyan educational system still suffers difficulties related to manpower. According to BTI (2016: 19), "The problem with the education system in Libya has not been its availability but rather its quality and capacity to prepare graduates for the local and international labour markets". In short, one of the challenging issues is the shortage of highly skilled graduates. A skilled workforce is the backbone of economic development. Rebuilding the country requires a competent workforce but the country may have challenges to recruit qualified personnel. To meet the demand, education and training becomes more important than ever.

\section{2. Professional Performance of Teachers' Scales}

From the perspective of performance management, the professional standards for teaching reflect a code of practice or performance yardstick for the purposes of teacher 
preparation and continuous professional development (Day, 2002; Evans, 2011; Louden, 2000; Tschannen-Moran, 2009). Louden (2000: 132) argued that professional standards, should "be brief, transparent, specialised, contextualised, focused on teaching and learning, and matched by strong assessments". However, the expectations for competent performance and whose notion of competence they reflect are not always straightforward (Shymansky, 1978).

A review of teacher standards suggest that teachers' performance consists the following: first, utilise innovative teaching tools and techniques to meet the learning needs (Louden, 2000); second, create and maintain appropriate students' behaviour in classroom settings (Day, 2002); third, interact with the school community effectively (Evans, 2011; Louden, 2000; Tschannen-Moran, 2009); fourth, maintain sense of professional identity and responsibility (Day, 2002); and lastly, engage in professional growth and development activities (Attinello et al., 2006; Evans, 2011; Louden, 2000; Tschannen-Moran, 2009).

According to Evans (2011), there are three main components of teacher professionalism: behavioural, attitudinal, and intellectual. While the latter one represents pedagogical content knowledge, the former two relates to attitudes held and what practitioners perform or achieve at work. This study adopts these main aspects of teacher professionalism, and expanded into five dimensions: 1) teaching skills, 2) management skills, 3) interpersonal skills, 4) discipline and regularity, and 5) professional development. While teaching skill is more concerned with the intellectual aspect of professionalism, management skills and interpersonal skills relates to the behavioural aspect of professionalism. The latter two - discipline and professional development - are related to attitudinal aspects of professionalism.

\section{Methodology}

The target population of the present study comprised Libyan primary and secondary school teachers of English in Zawiya, the west Region of Libya. Overall, it consists of 3036 teachers: 1973 teachers are distributed in 142 primary schools and 1063 teachers are distributed in 92 secondary schools. However, after using a stratified random sample, only 500 were selected for this study: 325 primary school teachers and 175 secondary schools teachers questionnaires were administered to the participating teachers, but only the returned questionnaires were 394, accounting or representing almost $79 \%$. After excluding those incomplete questionnaires, there were only $(\mathrm{N}=351)$ usable questionnaires which were used for analysis. The list of all schools and teachers was obtained from the relevant Executive District Offices (Ministry of Education) and those teachers chosen in the present study had at least one year of teaching experience at the schools. The data was collected over a period of time from (January to March, 2016).

\section{Results}

\subsection{Confirmatory Factor Analysis}

In order to test the model of professional performance schools the confirmatory factor analysis (CFA) model-fitting program is used. The model fit is evaluated by using four

International Journal of Management and Applied Research, 2016, Vol. 3, No. 3 
indices of the model goodness-of-fit: (1) the comparative fit index (CFI) (2) the chi-square statistics McDonald and Marsh (1990); (3) (RMSEA) between (0.08) to (0.10) indicates a mediocre fit Browne and Cudeck (1993) and would not employ a model a RMSEA greater than 0.1 (>0.1) (MacCallu um et al., 1996). (4) The minimum value of the discrepancy between the observed data and the proposed model divided by degrees of freedom (CMIN/DF) or normed chi-square (Marsh and Hocevar, 1985).

\subsection{The PPTS Model}

Figure (1) displays the results obtained through a CFA regarding the developed model for measuring teachers' professional performance, also known as (PPTS). Based on the results, this proposed model is free of the illogical correlation since it reaches or exceeds (1). This also implies that the CFA shows no problem regarding testing the validity of this model that comprises five dimension. Moreover, Figure (1) and Table (1) demonstrate that goodness of fit between the proposed model and the data exceeded the T-value, which is evidenced by the value of the Chi-Square (985.820) and the degree of freedom was (291) as well as the level of significance $(\mathrm{P}=0.000)$. The results also show that the normative Chi-Square (Chi-Square) was (3.888), which is lower than (5) and the value of relative strength index (CFI) was (0.893), which is even less than (0.90). Moreover, the root mean square error of approximation (RMSEA) was (0.083), which is higher than (0.080). This suggests the need for modifying the model of this study.

Figure 1: PPTS model with five- dimension before the amendment model

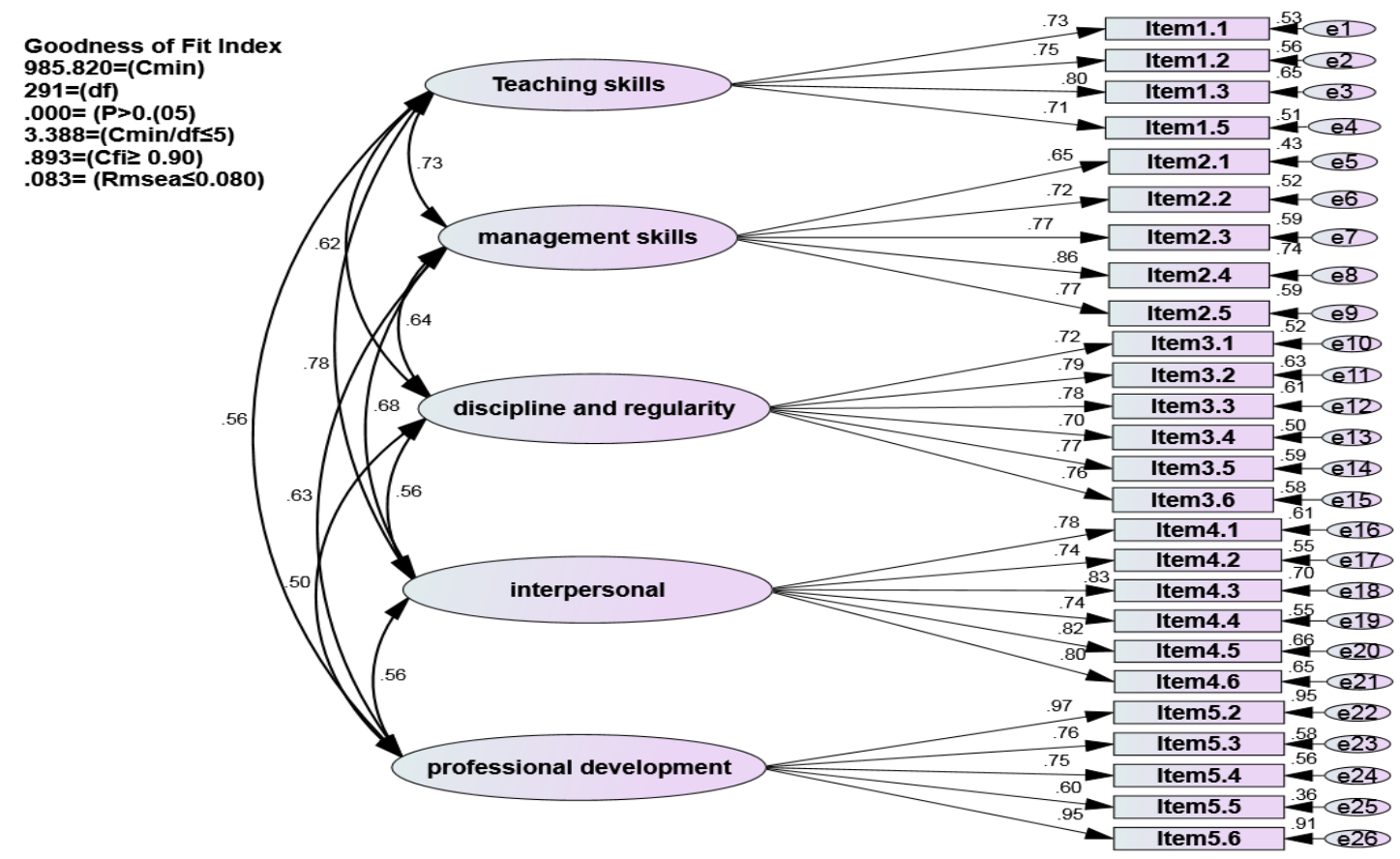

In order to modify this model, we followed was deleting some items, where they were weakest in the loading factor. as follow figure(2): (2.1),(3.4),(4.2),(4.4) and (5.5) The 
following figure 2 shows the (PPTS) model with five- dimension after the amendment.

Table 1: index value of (PPTS) model before and after modification

\begin{tabular}{cccc}
\hline Indicators consistency & $\begin{array}{c}\text { Index value before } \\
\text { modification }\end{array}$ & $\begin{array}{c}\text { Index value after } \\
\text { modification }\end{array}$ & $\begin{array}{c}\text { Function value on the } \\
\text { quality of conformity }\end{array}$ \\
\hline Cmin & 985.820 & 466.543 & --- \\
Df & 291 & 179 & --- \\
P-value & 0.000 & 0.000 & None \\
Cmin/Df & 3.388 & 2.606 & Less than (5) \\
CFI & 0.893 & 0.944 & More than (0.90) \\
Rmsea & 0.083 & 0.068 & Less than $(0.08)$ \\
\hline
\end{tabular}

Figure 2: PPTS model with five- dimension after the amendment model

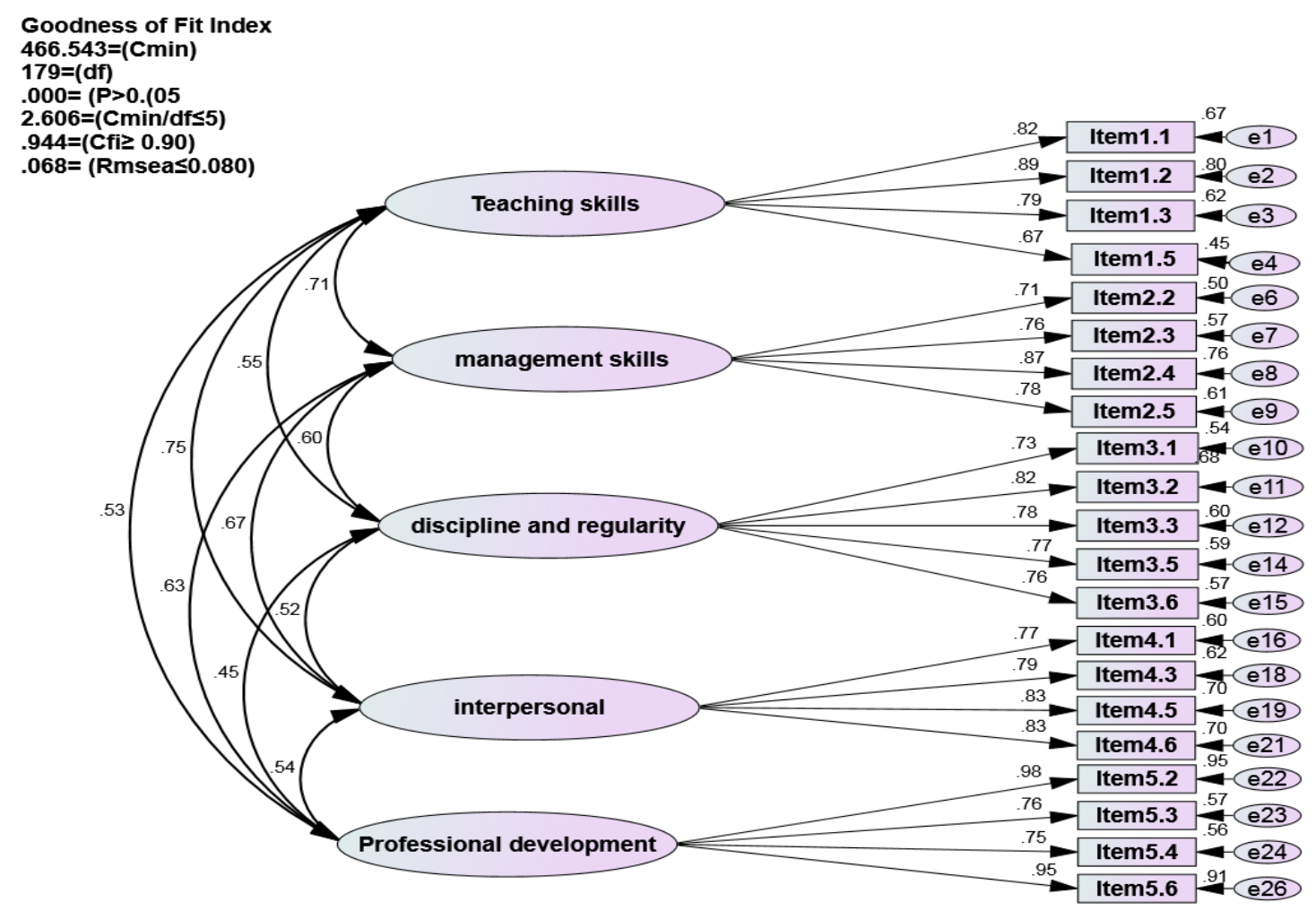

\subsection{Construct Validity and Reliability for five-factors (PPTS)}

According to Hair et al. (2006), the employment of factor loading composite reliability (CR) and average variance extracted (AVE) to determine the convergent validity if it equals to or greater than $0.5(\geq 0.5)$ and the composite reliability equals to or greater than 0.7 ( $\geq 0.7)$ if were recommended by Hair et al.(2006). Also, (AVE) reading values should be greater than $0.5(\geq 0.5)$ (Fornel and Larker, 1981).

\subsubsection{Construct Validity and Reliability for Teaching Skills:}

Based on the results, lodging for the parameters of this factor was in the range of (0.67 to 0.89), with all parameters which were estimated above $0.5(\geq 0.5)$. Moreover, the reliability was higher than $0.7(\geq 0.7)$ as it ranged from 0.817 to 0.839 . The AVE was 0.64 , which was also higher than $0.5(\geq 0.5)$. As a result, both reliability and validity were achieved by 
the first factor of the proposed model. Generally, the first dimension of the model was fit and fulfilled the construct as shown in Table (2).

Table 2: Construct Validity and Reliability of (PPTS) model- Teaching Skills

\begin{tabular}{ccccccccc}
\hline Dimension & $\begin{array}{c}\text { Items } \\
\text { Code }\end{array}$ & reliability & estimate & S. E. & C. R. & Loading & R & AVE \\
\hline \multirow{2}{*}{ Teaching } & 1.1 & 0.832 & 0.919 & 0.047 & 19.398 & 0.82 & 0.67 & 0.64 \\
skills & 1.2 & 0.817 & 1.000 & - & - & 0.89 & 0.80 & - \\
& 1.3 & 0.822 & 0.870 & 0.048 & 18.182 & 0.79 & 0.62 & - \\
\hline
\end{tabular}

\subsubsection{Construct Validity and Reliability for Management Skills:}

The results obtained from the validity and reliability tests showed that the lodging for the parameters of this factor ranged from 0.71 to 0.87 , with all parameters being above 0.5 ( $\geq 0.5)$. In addition, the reliability was higher than $0.7(\geq 0.7)$, ranging from 0.755 to 0.841 . The AVE was also found to be 0.61 , being higher than $0.5(\geq 0.5)$. Such result indicates that this second factor was reliable and valid, and that the second dimension of the proposed model was fit as depicted in Table (3).

Table 3: Construct Validity and Reliability of (PPTS) model- Management Skills

\begin{tabular}{ccccccccc}
\hline dimension & $\begin{array}{c}\text { Items } \\
\text { Code }\end{array}$ & reliability & estimate & S. E. & C. R. & Loading & R & AVE \\
\hline \multirow{3}{*}{ Management } & 2.2 & 0.841 & 0.820 & 0.055 & 14.911 & 0.71 & 0.50 & 0.61 \\
Skills & 2.3 & 0.821 & 0.897 & 0.055 & 16.411 & 0.76 & 0.57 & - \\
& 2.4 & 0.775 & 1.000 & - & - & 0.87 & 0.76 & - \\
\hline
\end{tabular}

\subsubsection{Construct Validity and Reliability for Discipline and Regularity:}

In this study, the lodging for the parameters factor ranged from 0.73 to 0.82 , with all parameters were above $0.5(\geq 0.5)$. The reliability was greater than $0.7(\geq 0.7)$, it ranged from 0.859 to 0.872 . In addition, the AVE reading was 0.60 where the value was greater than $0.5(\geq 0.5)$. Consequently, all results fulfilled the AVE, and the reliability discriminant validity of the third factor. In general, the third dimension of the (PPTS), model was fit and fulfilled the construct as depicted in Table (4).

Table 4: Construct Validity and Reliability of (PPTS) model- Discipline and Regularity

\begin{tabular}{ccccccccc}
\hline dimension & $\begin{array}{c}\text { Items } \\
\text { Code }\end{array}$ & reliability & estimate & S. E. & C. R. & Loading & R & AVE \\
& 3.1 & 0.872 & 0.909 & 0.067 & 13.572 & 0.73 & 0.54 & 0.60 \\
Discipline and & 3.2 & 0.859 & 0.920 & 0.060 & 15.377 & 0.82 & 0.68 & - \\
Regularity & 3.3 & 0.859 & 0.923 & 0.064 & 14.484 & 0.78 & 0.60 & - \\
& 3.5 & 0.862 & 0.916 & 0.064 & 14.251 & 0.77 & 0.59 & - \\
& 3.6 & 0.866 & 1.000 & - & - & 0.76 & 0.57 & - \\
\hline
\end{tabular}

\subsubsection{Construct Validity and Reliability for Interpersonal Skills:}

In the present study, the lodging for the parameters factor ranged from 0.77 to 0.83 , with all parameters were above $0.5(\geq 0.5)$. The reliability was greater than $0.7(\geq 0.7)$,

International Journal of Management and Applied Research, 2016, Vol. 3, No. 3 
it ranged from 0.879 to 0.889 . In addition, the AVE reading was 0.66 where the value was greater than $0.5(\geq 0.5)$. Consequently, all results fulfilled the AVE, and the reliability discriminant validity of the fourth factor. In general, the fourth dimension of the (PPTS), model was fit and fulfilled the construct as depicted in Table (5).

Table 5: Construct Validity and Reliability of (PPTS) model- Interpersonal Skills

\begin{tabular}{ccccccccc}
\hline Dimension & $\begin{array}{c}\text { Items } \\
\text { Code }\end{array}$ & reliability & estimate & S. E. & C. R. & Loading & R & AVE \\
& 4.1 & 0.889 & 0.955 & 0.058 & 16.362 & 0.77 & 0.60 & 0.66 \\
Interpersonal & 4.3 & 0.879 & 0.947 & 0.056 & 16.786 & 0.79 & 0.62 & - \\
Skills & 4.5 & 0.886 & 1.000 & - & - & 0.83 & 0.70 & - \\
& 4.6 & 0.888 & 0.989 & 0.055 & 18.133 & 0.83 & 0.70 & - \\
\hline
\end{tabular}

\subsubsection{Construct Validity and Reliability for Professional Development:}

In the current study, the lodging for the parameters factor ranged from 0.75 to 0.98 , with all parameters were above $0.5(\geq 0.5)$. The reliability was greater than $0.7(\geq 0.7)$, it ranged from 0.845 to 0.871 . In addition, the AVE reading was 0.75 where the value was greater than $0.5(\geq 0.5)$. Consequently, all results fulfilled the AVE, and the reliability discriminant validity of the fifth factor. In general, the fifth dimension of the (PPTS), model was fit and fulfilled the construct as depicted in Table (6).

Table 6: Construct Validity and Reliability of (PPTS) model- Professional Development

\begin{tabular}{ccccccccc}
\hline Dimension & $\begin{array}{c}\text { Items } \\
\text { Code }\end{array}$ & reliability & estimate & S. E. & C. R. & Loading & R & AVE \\
& 5.2 & 0.845 & 1.000 & - & - & 0.98 & 0.95 & 0.75 \\
Professional & 5.3 & 0.863 & 0.731 & 0.036 & 20.319 & 0.76 & 0.57 & - \\
Development & 5.4 & 0.871 & 0.739 & 0.037 & 19.850 & 0.75 & 0.56 & - \\
& 5.6 & 0.847 & 0.976 & 0.023 & 41.946 & 0.95 & 0.91 & - \\
\hline
\end{tabular}

\subsection{Fornell-Larcker Criterion}

In this study, Fornell -Larcker Criterion, suggesting that the AVE for each dimension of the main scale would be higher than the SV of all relations was used for the purpose of testing the predictive validity (discrimination) among the dimensions of the proposed model. This is shown in Table (7) presenting the results of the relations among the five dimension of the model.

Table 7: Covariance and the contrast between the extracted five-factor matrix (PPTS) models

\begin{tabular}{cccccc}
\hline P.D & I & D.R & M.S & T.S & Abbreviation dimension \\
\hline- & - & - & - & 0.64 & T.S \\
- & - & - & $\mathbf{0 . 6 1}$ & $\mathbf{0 . 5 0}$ & M.S \\
- & - & $\mathbf{0 . 6 0}$ & 0.36 & 0.30 & D.R \\
- & $\mathbf{0 . 6 6}$ & 0.27 & 0.45 & 0.56 & I \\
$\mathbf{0 . 7 5}$ & 0.29 & 0.20 & 0.40 & 0.28 & P.D \\
\hline
\end{tabular}

Based on the above results, the SV among the five dimensions is resulted from multiplying the value of correlation by itself. Moreover, the results demonstrate the AVE for every dimension of the proposed model was higher than the SV among all the 
dimensions. This indicates the above-mentioned Fornell -Larcker Criterion was fulfilled or met by the proposed model as the five dimensions achieved the required predictive validity.

\section{Discussion and Conclusion}

The study reported in this paper aimed at testing the validity of a proposed model for measuring teachers' performance. Being carried out among (PPTS) in Libyan primary and secondary school teachers in Zawiya, the study used a CFA through (SEM-AMOS). The model is based on five dimensions of teacher professionalism: teaching skills, management skills, discipline and regularity, interpersonal and professional development. The results of the current study showed that the proposed model is valid and reliable in measuring teachers' performance. In its five factors, the model exhibited the required average variance extracted (AVE), which was higher than $(0.50)$. The study also proved that the model achieved the required divergent validity, and that the AVE was higher than the divergent validity (SV) for all five factors. This suggests that it was consistent with Fornell-Larcker Criterion.

There are several limitations of this study that should be addressed for future research. First, since the study attempted to propose a model for measuring teachers' performance, the results seem to be indicative rather than conclusive. Therefore, in order to generalize the results, future studies should apply this model to measure professional performance among employees in other organizations and environments such as Arab, European and Asian countries. In addition, future research should not only replicate the results, but also develop a more comprehensive model for this purpose. A final limitation is that the results of this study may not be comprehensive, but they provide a useful starting point for further theoretical and empirical investigation of teachers' professional performance.

\section{References}

1. Attinello; J. R.; Lare; D. and Waters, F. (2006), "The Value of Teacher Portfolios for Evaluation and Professional Growth", National Association of Secondary School Principals NASSP Bulletin, Vol. 90, No. 2, pp. 132-152. https://doi.org/10.1177/0192636506288864

2. BTI (2016), Libya Country Report, [Online] available from: https://www.bti-project.org/fileadmin/files/BTI/Downloads/Reports/2016/pdf/BTI 2016_Libya.pdf [accessed on 28 August 2016].

3. Day, C. (2002), "School reform and transitions in teacher professionalism and identity", International Journal of Educational Research, Vol. 37, No. 8, pp. 677-692. https://doi.org/10.1016/S0883-0355(03)00065-X.

4. Evans, L. (2011), “The 'shape' of teacher professionalism in England: professional standards, performance management, professional development and the changes proposed in the 2010 White Paper", British Educational Research Journal, Vol. 37 , No. 5, pp. 851-870. https://doi.org/10.1080/01411926.2011.607231

5. Fornell, C., and Larcker, D. F. (1981), "Evaluating Structural Equation Models 
with Unobservable Variables and Measurement Error", Journal of Marketing Research, Vol. 18, No. 1, pp. 39-50.

6. Hair, J., Black, B. Babin, B., Anderson, R. and Tatham, R. (2006). Multivariate Data Analysis, ${ }^{\text {th }}$ edition, Upper Saddle River, NJ: Prentice-Hall.

7. ICEF Monitor (2014), Libya struggling to meet massive demand for higher education, [Online] available from:

http://monitor.icef.com/2014/07/libya-struggling-to-meet-massive-demand-for-hig her-education/ [accessed on 28 August 2016].

8. Louden, W. (2000), "Standards for Standards: The Development of Australian Professional Standards for Teaching", Australian Journal of Education, Vol. 44, No. 2, pp. 118-134. https://doi.org/10.1177/000494410004400203

9. MacCallum, R.C., Browne, M.W., and Sugawara, H., M. (1996), "Power Analysis and Determination of Sample Size for Covariance Structure Modelling", Psychological Methods, Vol. 1, No. 2, pp. 130-49. https://doi.org/10.1037/1082-989X.1.2.130

10. Marsh, H. W. and Hocevar, D. (1985), “Application of confirmatory factor analysis to the study of self-concept: First-and higher order factor models and their invariance across groups", Psychological bulletin, Vol. 97, No. 3, pp. 562-582. https://doi.org/10.1037/0033-2909.97.3.562.

11. McDonald, R. P. and Marsh, H. W. (1990), "Choosing a multivariate model: No centrality and goodness of fit", Psychological Bulletin, Vol. 107, No. 2, pp. 247-255. https://doi.org/10.1037/0033-2909.107.2.247

12. Rose, M. (2015), Education in North Africa since independence: Libya, British Council [Online] available from:

http://www.britishcouncil.tn/sites/default/files/bc_country_profile_libya_v4.pdf [accessed on 28 August 2016].

13. Shymansky, J. (1978), “Assessing teacher performance in the classroom: Pattern analysis applied to interaction data", Studies in Educational Evaluation, Vol. 4, No. 2, pp. 99-106. https://doi.org/10.1016/0191-491X(78)90005-6

14. Tschannen-Moran, M. (2009), "Fostering Teacher Professionalism in Schools: The Role of Leadership Orientation and Trust", Educational Administration Quarterly, Vol. 45, No. 2, pp. 217-247. https://doi.org/10.1177/0013161X08330501

\section{Appendix}

\begin{tabular}{|l|l|l|}
\hline $\begin{array}{l}\text { Measures used for } \\
\text { ( PPTS ) dimension }\end{array}$ & Items & \multicolumn{1}{c|}{ Description } \\
\hline Teaching Skills & 1.1 & I use different methods of teaching. \\
\cline { 2 - 3 } & 1.2 & I teach every student according to his abilities. \\
\cline { 2 - 3 } & 1.3 & If any student ask question I try to satisfy him at every level. \\
\cline { 2 - 3 } & 1.5 & I make no injustice in marking the papers. \\
\hline Management Skills & 2.2 & Apart from teaching I fulfill other responsibilities very nicely. \\
\cline { 2 - 3 } & 2.3 & I don't let co- curricular activities to affect my class teaching \\
\cline { 2 - 3 } & 2.4 & I don't let my domestic affairs to interfere in my duty \\
\cline { 2 - 3 } & 2.5 & If someone changes my responsibilities then I adjust myself. \\
\hline
\end{tabular}

International Journal of Management and Applied Research, 2016, Vol. 3, No. 3 


\begin{tabular}{|c|c|c|}
\hline \multirow{5}{*}{$\begin{array}{l}\text { Discipline \& } \\
\text { Regularity }\end{array}$} & 3.1 & I come to school regularly. \\
\hline & 3.2 & When present at school I attain my class on time. \\
\hline & 3.3 & I don't do irrelevant activity in my period. \\
\hline & 3.5 & I fulfill my assigned activities on time. \\
\hline & 3.6 & I maintain discipline in my class. \\
\hline \multirow[t]{4}{*}{ Interpersonal } & 4.1 & Apart from teaching I try to solve any problem of the student \\
\hline & 4.3 & I enjoy good relations with my colleagues. \\
\hline & 4.5 & I co-operate with my colleagues in any work. \\
\hline & 4.6 & I consult my colleagues in solving of my class problems. \\
\hline \multirow[t]{4}{*}{$\begin{array}{l}\text { Professional } \\
\text { Development }\end{array}$} & 5.2 & $\begin{array}{l}\text { I conduct research and educational studies and take part or } \\
\text { participate in research competitions }\end{array}$ \\
\hline & 5.3 & $\begin{array}{l}\text { I enrich myself with reading and knowing what new in the } \\
\text { English Language is. }\end{array}$ \\
\hline & 5.4 & $\begin{array}{l}\text { I make sure that I develop and employ contemporary teaching } \\
\text { techniques and use them in effectively delivering information to } \\
\text { the learner. }\end{array}$ \\
\hline & 5.6 & $\begin{array}{l}\text { I try to keep up with the developments in the field of learning } \\
\text { and teaching theory. }\end{array}$ \\
\hline
\end{tabular}

International Journal of Management and Applied Research, 2016, Vol. 3, No. 3 